\title{
DESENVOLVIMENTO E CONSTRUÇÃO DE UM DESTILADOR SOLAR PARA DESSALINIZAÇÃO DE ÁGUA SALGADA EM DIFERENTES CONCENTRAÇÕES DE SAIS
}

\author{
E. V. FARIA*, I. F. B. ALVES, B. S. A. ARAÚJO, L. H. S. BONTEMPO, M. N. LIMA, \\ L. C. C. B. OLIVEIRA \\ Universidade Federal do Triângulo Mineiro, UFTM, ICTE \\ *e-mail: erica-victor@hotmail.com
}

\begin{abstract}
RESUMO
Atualmente, uma significativa parcela da população mundial sofre com a escassez de água. Uma alternativa à este problema é o consumo de água provinda de processos de dessalinização, como, a destilação solar, que destaca-se por usar como fonte energética a radiação solar. A proposta do trabalho é a construção de um destilador solar com cobertura piramidal utilizando materiais de baixo custo, composto por uma cobertura de vidro, assadeira de alumínio como a base da bacia, garrafas PET para coleta da água destilada. Foi construído assim, um destilador de $0,2025 \mathrm{~m}^{2}$. Para efeitos de melhoria no equipamento, identificou-se a partir da análise estatística as variáveis mais significativas na produção de destilado, realizando testes no destilador a partir de um planejamento composto central. A eficiência do equipamento foi medida através da produção e qualidade da água. Ao se analisar a água destilada final, constatou-se que os valores de $\mathrm{pH}$ e condutividade classificam-na como apropriada ao consumo humano. De acordo com o planejamento de experimentos, obteve-se que a variável que mais influente sobre a produção de água destilada foi a profundidade da bacia, seguida da salinidade da água e espessura do isolamento. A maior produção de destilado obtida foi de $580 \mathrm{~mL}$ de água atingindo-se a temperatura máxima de $66^{\circ} \mathrm{C}$, na condição de mínima profundidade da bacia. Os testes mostraram que o destilador solar construído funciona adequadamente.
\end{abstract}

\section{INTRODUÇÃO}

A escassez de água vem se tornando um assunto cada vez mais recorrente. Sabe-se que apesar de ser um dos maiores bens da humanidade, a água não é inesgotável e sua utilização negligente e desperdícios rotineiros vêm acarretando a sua falta. Em algumas regiões a carência extrema de água de boa qualidade força as populações a consumirem águas com elevados níveis de contaminação química (sais) e biológica com resultando em danos à saúde.
De acordo com Cravo e Cardoso (1996), o consumo de água doce no mundo aumenta a um ritmo superior ao do crescimento da população, restando como uma das saídas para satisfazer às necessidades hídricas a produção de água potável a partir da água do mar ou de águas salobras de açudes e poços.

Existem diversas tecnologias para a produção de água potável, a partir de águas salgadas, tais como, osmose reversa, eletrodiálise, destilação flash multi-estágio, destilação multiefeito e a destilação solar. Dentre estas tecnologias, a destilação solar se 
apresenta como uma alternativa interessante, uma vez que utiliza uma fonte de energia gratuita e abundante, de fácil operação, não gera poluição e é eficaz no tratamento de águas, sendo assim uma solução integrada tanto para a escassez de água potável quanto para os problemas energéticos e ambientais também enfrentados.

A energia solar aliada à destilação é uma forma promissora de se obter água potável. Essa operação imita, em pequena escala, o ciclo natural da água, evaporando a água poluída e posteriormente condensando-a obtendo ao final do processo água destilada. Embora seja uma tecnologia simples, a purificação de água através da destilação solar é bastante eficaz, produzindo água com alto grau de pureza, superior às águas comerciais engarrafadas (FOSTER \& AMOS, 2005).

Um estudo realizado por Mota e Andrade (1986) mostrou que a destilação solar elimina completamente sais, metais pesados, bactérias e micróbios presentes em águas poluídas, assim como, a remoção bemsucedida de diversos pesticidas, devido a exposição à radiação ultravioleta e altas temperaturas.

Levando em consideração a escassez de água evidenciada ao longo período de estiagem enfrentado na região do Triângulo Mineiro durante o segundo semestre de 2014, no qual a cidade de Uberaba chegou a decretar estado de emergência, sendo considerada a pior seca dos últimos 50 anos. A motivação deste projeto consiste na importância de se tratar a água e reaproveitála ao consumo humano.

\section{METODOLOGIA}

\subsection{Construção do Destilador}

O correto dimensionamento do destilador solar depende de vários fatores para se obter uma produção de água destilada desejada, parâmetros como intensidade de radiação solar, velocidade do vento, orientação do destilador, local da instalação, vedação, dentre outros (ALVES, 2008).

\subsubsection{Bacia}

A fim de promover eficiência as paredes internas, inclusive o fundo da bacia, serão de alumínio, a fim de facilitar a troca térmica do calor absorvido por estas com a água. Ainda, será utilizada tinta acrílica na cor preta, para pintar as partes em alumínio para aumentar a absorção, diminuindo a reflexão, da radiação solar na bacia.

\subsubsection{Suporte e Cobertura}

A cobertura do destilador deve ser constituída de material transparente para proporcionar a transmissão da radiação solar. Para a confecção da cobertura e suporte do destilador foi escolhido o vidro, pois este gera maior efeito estufa que o plástico, alta transmissão da radiação solar, baixa transmissão da radiação de baixa temperatura, umidade da água e alta estabilidade de suas propriedades mesmo após muitas horas de exposição (LUIZ, 1985).

Além disso, foi escolhida a forma de uma pirâmide, em que, as faces de vidro permitem a incidência de raios solares durante o tempo de exposição, independentemente da posição do sol. O ângulo ótimo entre a cobertura de vidro e a base do equipamento depende da latitude do local onde o mesmo está inserido, pois este deve ser selecionado de forma a obter-se a maior incidência de radiação solar possível. Segundo Samee et al. (2005), o ângulo ótimo para uma cobertura equivale à latitude local, sendo neste trabalho adotado um ângulo de $20^{\circ}$.

Além disso, a temperatura da cobertura é um dos parâmetros que mais influencia diretamente a produtividade na destilação solar. A diminuição desta temperatura leva a um incremento de produtividade, uma vez que, um aumento entre a diferença de temperatura da cobertura e bacia, provoca um acréscimo na transferência de calor 
convectiva e evaporativa entre eles, devido a um aumento da circulação natural da massa de ar no interior da própria unidade. Com isso, a proposta de uma cobertura de geometria piramidal também influência neste aspecto, visto que, enquanto um dos lados da cobertura recebe a incidência direta de raios solares, os outros lados não a recebem e consequentemente a temperatura nestes é menor, favorecendo a condensação.

Para a dimensionalização da cobertura de acordo com o ângulo necessário, $20^{\circ}$, foram usadas relações trigonométricas, como mostra a Figura 1.

Figura 1 - Desenho esquemático da cobertura do destilador (pirâmide).

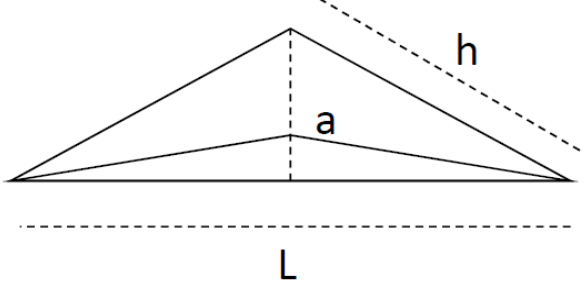

Fonte: Autor (2014).

A planilha de cálculo das dimensões das faces da cobertura de vidro (pirâmide) está apresentada na Tabela 1. A base utilizada é quadrada com lado base (L) de $50 \mathrm{~cm}$ e um ângulo faces $(\alpha)$ de $20^{\circ}$.

Tabela 1 - Planilha de cálculo das dimensões das faces da cobertura de vidro (pirâmide).

\begin{tabular}{cc}
\hline Equacionamento & Dimensão [cm] \\
\hline $\mathrm{H}=\operatorname{tg}(\alpha \mathrm{L} / 2)$ & 9,10 \\
$\mathrm{~A}=\mathrm{H} / \mathrm{sen} \alpha$ & 26,60 \\
$\mathrm{~h}=\left(\left(\mathrm{a}^{2}+(\mathrm{L} / 2)^{2}\right)^{1 / 2}\right.$ & 36,51 \\
\hline
\end{tabular}

Fonte: Autor (2014).

\subsubsection{Isolamento}

Visando evitar perdas de calor para o ambiente, todo o recipiente, exceto a cobertura, deve ser isolado com uma camada intermediária de isopor, para as partes encaixáveis do projeto será utilizado silicone como material para vedação.
A fim de avaliar a influência deste parâmetro no rendimento do destilado produzido, serão testadas diversas espessuras de isopor. Um esquema ilustrativo está demonstrado como mostra na Figura 2.

Figura 2 - Vista frontal da representação esquemática do destilador solar.

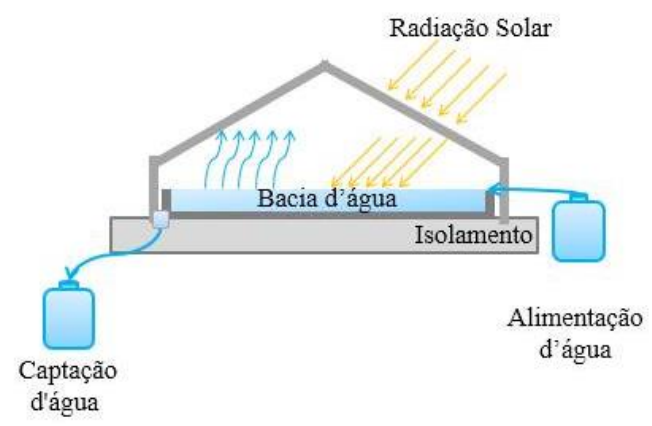

Fonte: Autor (2014).

\subsection{Preparo da Água a ser Destilada}

Devido à dificuldade em transportar e armazenar água do mar natural optou-se pelo preparo de uma solução de água do mar artificial. De acordo com Tabela 2.

Tabela 2 - Composição da água do mar.

\begin{tabular}{cc}
\hline Componente & Concentração g/L \\
\hline $\mathrm{NaCl}$ & 24,53 \\
$\mathrm{MgCl}_{2}$ & 5,20 \\
$\mathrm{Na}_{2} \mathrm{SO}_{4}$ & 4,09 \\
$\mathrm{CaCl}_{2}$ & 1,16 \\
$\mathrm{KCl}$ & 0,695 \\
$\mathrm{NaHCO}$ & 0,201 \\
$\mathrm{KBr}$ & 0,101 \\
$\mathrm{H}_{3} \mathrm{BO}_{3}$ & 0,027 \\
$\mathrm{SrCl}_{2}$ & 0,025 \\
$\mathrm{NaF}$ & 0,003 \\
$\mathrm{Ba}\left(\mathrm{NO}_{3}\right)_{2}$ & 0,0000994 \\
$\mathrm{Mn}\left(\mathrm{NO}_{2}\right)_{2}$ & 0,0000340 \\
$\mathrm{Cu}\left(\mathrm{NO}_{3}\right)_{2}$ & 0,0000308 \\
$\mathrm{Zn}\left(\mathrm{NO}_{3}\right)_{2}$ & 0,0000096 \\
$\mathrm{~Pb}\left(\mathrm{NO}_{3}\right)_{2}$ & 0,0000066 \\
$\mathrm{Ag} \mathrm{NO}$ & 0,00000049 \\
\hline
\end{tabular}

Fonte: Norma ASTM D 1141 (1998). 
Na Tabela 2 são mostrados os componentes da solução de água do mar artificial de acordo com a norma ASTM D 1141 de 1998. No entanto, devido a falta de reagentes, optou-se por preparar a água para os testes apenas com Cloreto de Sódio, por apresentar concentração muito maior que os demais componentes.

\subsection{Procedimento Operacional Padrão}

Para construção do destilador adotou-se o modelo esquematizado na Figura 2. Inicialmente realizou a confecção da cobertura em formato de pirâmide e do corpo do destilador, em vidro, no qual estiveram acopladas as canaletas do mesmo material. Esta etapa foi terceirizada por meio da vidraçaria.

Com a cobertura e corpo do destilador prontos, foi encaixada a bacia de alumínio, de $45 \mathrm{~cm}$ de lado, em uma base de isopor, confeccionada pelos autores, com isso, a área útil do destilador 0,2025 $\mathrm{m}^{2}$. Para absorver de forma mais eficiente a incidência dos raios solares, diminuindo a reflexão, pintou-se o fundo da bacia com tinta preta acrílica, na qual foi adicionado o quantidade de água a ser destilada.

Figura 3 - Destilador solar utilizado nos testes.

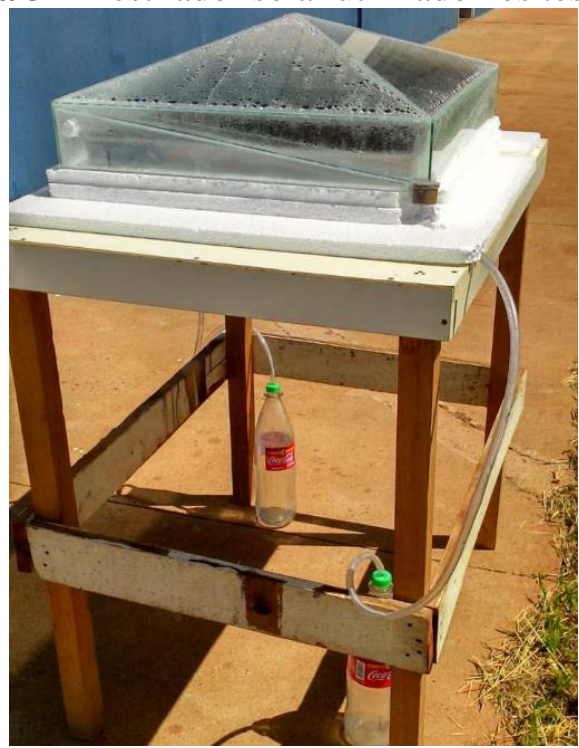

Fonte: Autor (2015).
Em seguida, foram encaixadas mangueiras transparentes nas extremidades das canaletas, para que a água recolhida fosse armazenada em garrafas PET graduadas pelos autores.

Além disso, para a avaliação da espessura do isolamento, em alguns testes as laterais do destilador foram revestidas com isopor, em diferentes espessuras. A vedação foi realizada utilizando silicone em todas as junções do destilador. Na Figura 3 está representado o aparato pronto para os testes.

\subsection{Operação do Destilador}

Foram realizados testes diários de segunda a sexta num período compreendido entre as 8:00 e 16:00. Estes foram realizados de acordo com o planejamento experimental elaborado pelo grupo (Tabela 4), em que foram utilizadas diferentes espessuras de isolamento, profundidade $\mathrm{da}$ bacia $\mathrm{e}$ concentração de sais na água a ser destilada.

Antes do início da operação do destilador é necessária uma fase de preparação. Inicialmente a mesa suporte é posta no local estratégico, no qual o destilador haja incidência solar o dia todo. A cobertura foi devidamente limpa e desinfetada, e as garrafas PET lavadas, para não haver contaminação do produto. Foi então pesada a quantidade de água e sal referente ao experimento do dia, e devidamente misturados foram adicionados na bacia de alumínio.

Para dar início ao teste colocou-se à base de isopor na mesa juntamente com a bacia de alumínio e a solução a ser destilada. Em seguida a cobertura com as mangueiras é acoplada a esse conjunto. Dependendo do referido experimento foi colocada a devida espessura de isopor para isolamento. Por fim foram encaixadas as garrafas PET ás mangueiras.

Com o aparato devidamente montado, foram feitas realizadas medições em tempos de uma hora da temperatura ambiente, em 
cada face cobertura do destilador, do ambiente interno do destilador e da água da bacia, com auxílio de um multímetro digital, também foi medida a cada hora a velocidade do vento utilizando-se um anemômetro de fio quente. Conforme a temperatura no interior do destilador aumenta começa a ocorrer a evaporação da água, que ao colidir com a cobertura de vidro se condensa e escorre até as extremidades, sendo coletadas pelas canaletas e armazenadas nas garrafas PET através das mangueiras. Para manter a quantidade de água dentro do destilador constante, esta foi reposta com auxílio de conta gotas e marcações feitas na bacia.

Todos os experimentos realizados tiveram seus dados devidamente registrados para futuro tratamento.

\section{RESULTADOS E DISCUSSÕES}

\subsection{Análise da Qualidade do Produto}

Nessa etapa do trabalho foi analisado o produto, água destilada. Os testes foram feitos no laboratório de química da UFTM, onde pôde-se analisar algumas características básicas de acordo com os aparatos que o laboratório possui. Foram analisados o $\mathrm{pH}$ e a condutividade da água destilado.

Os dados de $\mathrm{pH}$ e condutividade obtidos do produto estão apresentados na Tabela 3, foram selecionadas aleatoriamente as amostras a ser analisadas. Em posse desses valores e dos padrões apresentados, observou que o $\mathrm{pH}$ das amostras esteve dentro da faixa recomendável para consumo humano de acordo com a Portaria 2914 do Ministério da Saúde (6 a 9,5). A condutividade das amostras destiladas foi baixa e também estiveram dentro da faixa permissível $(0-800 \mu \mathrm{S})$, referido a água doce. Se comparado com a condutividade da água salina houve uma diminuição aguçada nos valores.
Tabela 3 - Valores de $\mathrm{pH}$ e condutividade da água destilada.

\begin{tabular}{ccc}
\hline Teste & $\mathbf{p H}$ & Condutividade $(\boldsymbol{\mu S})$ \\
\hline 10 & 8,38 & 10,0 \\
5 & 8,15 & 7,50 \\
3 & 6,67 & 24,40 \\
4 & 5,36 & 17,90 \\
1 & 5,40 & 27,20 \\
2 & 6,80 & 11,57 \\
16 & 6,80 & 11,42 \\
\hline
\end{tabular}

Fonte: Autor (2015).

Dados de condutividade da água salina usados nos experimentos foram medidos inicialmente. Quando comparados com os valores finais houve uma queda acentuada na condutividade. O valor de $29100 \mu \mathrm{S}$ foi obtido da água com sal do teste 10, apresentando estar na faixa destinada a água salina, acima de $4800 \mu \mathrm{S}$, a água destilada do referido dia apresentou o valor de $10 \mu \mathrm{S}$. A medida da água destilada do laboratório apresentou uma condutividade de $15 \mu \mathrm{S}$, se comparada com o produto obtido maior parte dos testes, a água destilada pelo equipamento apresentou valores de condutividade semelhantes, ou até mesmo mais baixos à do laboratório.

\subsection{Análise de Variáveis que Causam Efeitos no Produto Final}

A análise das variáveis que causam efeito no produto final foi realizada através da metodologia estatística utilizando planejamento composto central com três réplicas no ponto central e a técnica de superfície de resposta, com suporte do software Statistica para a comparação dos efeitos causados pela espessura do isolamento, altura da bacia e salinidade da água, como apresentado na Tabela 4. 
Tabela 4 - Planejamento composto central.

\begin{tabular}{ccccc}
\hline $\mathbf{N}^{\mathbf{1}}$ & $\begin{array}{c}\text { Isolante } \\
(\mathbf{c m})\end{array}$ & $\begin{array}{c}\text { Bacia } \\
(\mathbf{c m})\end{array}$ & $\begin{array}{c}\text { Salinidade } \\
\left(\mathbf{g}_{\text {sal }} / \mathbf{g} \text { gua }\right)\end{array}$ & $\begin{array}{c}\text { Destilado } \\
(\mathbf{m L / d i a})\end{array}$ \\
\hline $\mathbf{1}$ & 1,20 & 1,49 & 10,46 & 460 \\
$\mathbf{2}$ & 1,20 & 3,99 & 27,96 & 380 \\
$\mathbf{3}$ & 3,20 & 1,49 & 27,96 & 520 \\
$\mathbf{4}$ & 3,20 & 3,99 & 10,46 & 340 \\
$\mathbf{5}$ & 2,00 & 2,50 & 17,50 & 430 \\
$\mathbf{6}$ & 1,20 & 1,49 & 27,96 & 525 \\
$\mathbf{7}$ & 1,20 & 3,99 & 10,46 & 360 \\
$\mathbf{8}$ & 3,20 & 1,49 & 10,46 & 520 \\
$\mathbf{9}$ & 3,20 & 3,99 & 27,96 & 235 \\
$\mathbf{1 0}$ & 2,00 & 2,50 & 17,50 & 400 \\
$\mathbf{1 1}$ & 0,00 & 2,50 & 17,50 & 460 \\
$\mathbf{1 2}$ & 4,00 & 2,50 & 17,50 & 500 \\
$\mathbf{1 3}$ & 2,00 & 1,00 & 17,50 & 580 \\
$\mathbf{1 4}$ & 2,00 & 5,00 & 17,50 & 210 \\
$\mathbf{1 5}$ & 2,00 & 2,50 & 0,00 & 500 \\
$\mathbf{1 6}$ & 2,00 & 2,50 & 35,00 & 200 \\
$\mathbf{1 7}$ & 2,00 & 2,50 & 17,50 & 390 \\
\hline
\end{tabular}

Fonte: Autor (2015).

Devido a dependência dos experimentos com as condições climáticas, como a radiação solar e a velocidade do vento, fatores que não podem ser manipulados, procurou-se realizar cada teste em condições parecidas, mas não idênticas.

A fim de suprir o fato, o planejamento foi realizado com nível de significância de $15 \%$. A análise de variância da regressão foi apresentada através do teste $\mathrm{F}$ e coeficiente de correlação $\mathrm{R}^{2}$, como observado na Tabela 5 .

Tabela 5 - Efeitos das variáveis sobre a produção de destilado $\left(\mathrm{R}^{2}=0,8423\right)$.

\begin{tabular}{cccc}
\hline Fator & Parâmetro & Desvio & Significância \\
\hline Média & 403,32 & 25,02 & 0,00 \\
$\begin{array}{c}\text { 1 Espessura } \\
\text { Isolamento (Q) }\end{array}$ & 28,86 & 16,56 & 0,11 \\
2 Profundidade & $-97,73$ & 15,65 & 0,00 \\
da Bacia (L) & $-38,38$ & 15,65 & 0,03 \\
3 Salinidade (L) & $-17,57$ & 16,56 & 0,31 \\
3 Salinidade (Q) & $-27,50$ & 20,41 & 0,21 \\
1L by 2L & $-23,75$ & 20,41 & 0,27 \\
\hline 1L by 3L & & &
\end{tabular}

Fonte: Autor (2015).
Foi realizada uma análise de múltipla regressão, sendo os parâmetros estimados por mínimos quadrados.

Ao analisar os resultados obtidos é notável que a variável de maior influência é a profundidade da bacia, seguidas da salinidade e da espessura do isolamento. Tais implicações estão de acordo com a literatura abordada neste trabalho.

Para facilitar a visualização dos efeitos, foram plotadas superfícies de resposta para estas variáveis, acopladas duas a duas, fixando a terceira no nível zero.

Ao avaliar a Figura 4 que representa a superfície de resposta da profundidade da bacia com a espessura do isolamento, mantendo-se a salinidade da água no nível zero, nota-se que os maiores valores de produção de destilado foram obtidos para maiores valores de espessura e menores valores de profundidade da bacia, como esperado.

Figura 4 - Superfície de resposta da profundidade da bacia versus espessura do isolamento

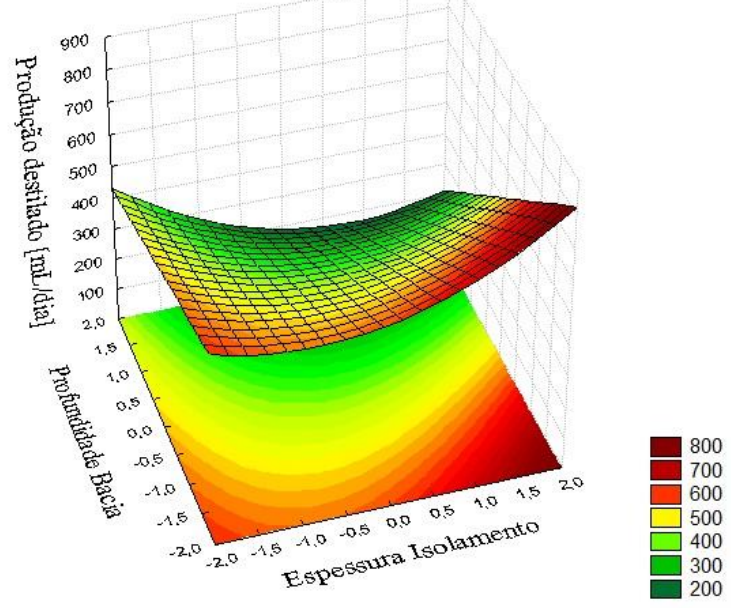

Fonte: Autor (2015).

Ao avaliar a Figura 5 que representa a superfície de resposta da profundidade da bacia com a salinidade da água mantendo-se a espessura do isolamento no nível zero, nota-se que os maiores valores de produção de 
destilado foram obtidos para menores valores de profundidade da bacia e salinidade.

Figura 5 - Superfície de resposta da profundidade da bacia por salinidade da água

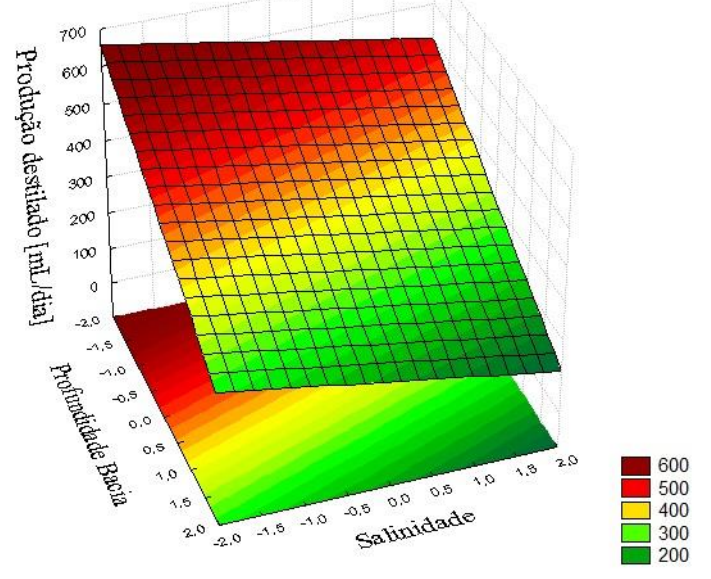

Fonte: Autor (2015).

Ao avaliar a Figura 6 que representa a superfície de resposta da espessura do isolamento com a salinidade da água mantendo-se a profundidade da bacia no nível zero, nota-se que os maiores valores de produção de destilado foram obtidos para menores valores de salinidade da água e maiores valores de espessura do isolamento.

De posse dos efeitos do planejamento

composto central e das superfícies de resposta observa-se que maiores valores de destilado foram obtidos para menores valores de massa de água na bacia da bacia, em concordância com Tiwari e Tiwari (2007), pois quanto menor a quantidade de água no equipamento maior a facilidade em aquecê-la até que haja a ebulição.

A segunda variável de maior influência é a salinidade, sendo que menores valores de salinidade contribuem para maior produção de destilado. Ao passo que para maiores valores de espessura do isolamento tem-se maior produção de destilado. Esse efeito mostra-se pequeno diante dos demais, o que pode ser explicado pelo fato das laterais do destilador serem de vidro, que é um bom isolante térmico. Além disso, o sistema estava vedado de forma eficiente, uma vez que o fundo do destilador foi comportado por uma placa de isopor.

Figura 6 - Superfície de resposta da espessura do isolamento e salinidade da água

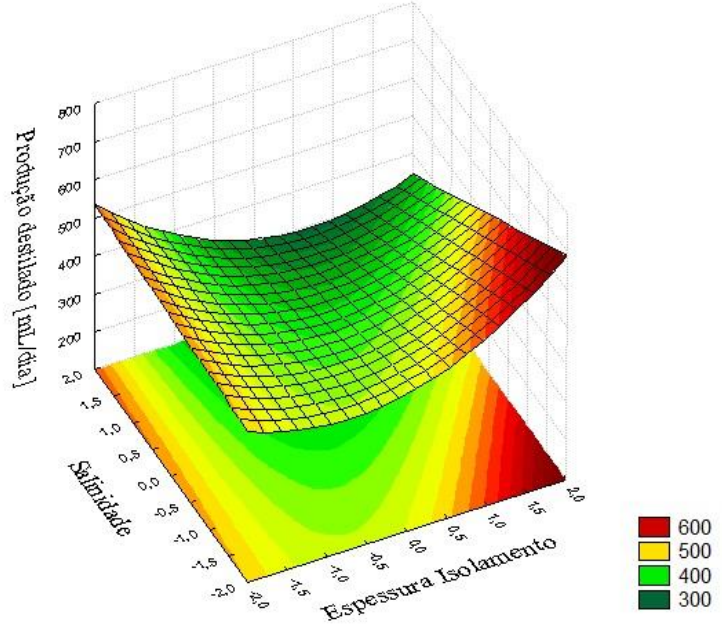

Fonte: Autor (2015).

Vale ressaltar que as condições climáticas têm grande influência sobre os testes, visto que a radiação solar incidente tem grande significância no processo, pois é a única fonte de calor. Ainda, para facilitar a visualização, foi calculada a eficiência de cada experimento, de acordo com a Equação 1.

$\eta=\frac{P \lambda}{H_{S} A s 3600}$

\section{Sendo:}

- $\quad \mathrm{P}$ a produção de água destilada $\left(\mathrm{L} / \mathrm{m}^{2}\right)$;

- As a área útil do destilador $\left(\mathrm{m}^{2}\right)$;

- $\mathrm{H}_{\mathrm{s}}$ o valor da radiação solar recebida durante a operação $\left(\mathrm{kWh} / \mathrm{m}^{2}\right)$;

- $\quad \lambda$ o calor latente de evaporação da água $(\mathrm{J} / \mathrm{kg})$.

Estão mostrados na Tabela 6 a radiação solar incidente total sobre cada teste, de 8:00 horas às 16:00 horas, a produção e a eficiência. 
Tabela 6: Eficiência dos testes.

\begin{tabular}{cccc}
\hline Teste & $\begin{array}{c}\text { Destilado } \\
\mathbf{P}(\mathbf{L})\end{array}$ & $\begin{array}{c}\text { Radiação } \\
\mathbf{H}_{\mathbf{s}}\left(\mathbf{k} \mathbf{W h} / \mathbf{m}^{\mathbf{2}}\right)\end{array}$ & $\begin{array}{c}\text { Eficiência } \\
\mathbf{\eta}(\mathbf{\%})\end{array}$ \\
\hline $\mathbf{1}$ & 0,46 & 4,872 & 31,5 \\
$\mathbf{2}$ & 0,38 & 4,716 & 26,9 \\
$\mathbf{3}$ & 0,52 & 4,451 & 38,9 \\
$\mathbf{4}$ & 0,34 & 3,470 & 32,7 \\
$\mathbf{5}$ & 0,43 & 4,742 & 30,2 \\
$\mathbf{6}$ & 0,53 & 4,709 & 37,2 \\
$\mathbf{7}$ & 0,36 & 4,776 & 25,1 \\
$\mathbf{8}$ & 0,52 & 4,675 & 37,1 \\
$\mathbf{9}$ & 0,24 & 4,108 & 19,1 \\
$\mathbf{1 0}$ & 0,40 & 4,860 & 27,4 \\
$\mathbf{1 1}$ & 0,46 & 4,206 & 36,5 \\
$\mathbf{1 2}$ & 0,50 & 4,752 & 35,1 \\
$\mathbf{1 3}$ & 0,58 & 3,424 & 56,5 \\
$\mathbf{1 4}$ & 0,21 & 4,395 & 15,9 \\
$\mathbf{1 5}$ & 0,50 & 3,478 & 47,9 \\
$\mathbf{1 6}$ & 0,20 & 3,090 & 15,2 \\
$\mathbf{1 7}$ & 0,39 & 4,449 & 29,2 \\
\hline
\end{tabular}

Fonte: Autor (2015).

Ao analisar individualmente os testes observa-se que a maior eficiência, cerca de $56,5 \%$, e produção de destilado foram obtidas no teste 13 , sendo este realizado com o menor nível de profundidade de bacia, e a menor eficiência foi obtida no experimento realizado com o maior nível de profundidade de bacia, reafirmando que esta é a variável mais influente no processo. É importante ressaltar que de acordo com Maluf (2005) a eficiência de um destilador solar máxima é em média $60 \%$, devido a difusão de radiação solar e perdas de calor no destilador.

Não foi possível afirmar nada sobre a influência da velocidade do vento sobre os testes, e não foi possível realizar essa medição em todos os testes, como visto na Tabela 6 , devido à indisponibilidade do anemômetro. Os dados de radiação solar foram obtidos no site do Instituto Nacional de Meteorologia, para a cidade mais próxima do local aonde foram realizados os testes, Conceição das Alagoas, Minas Gerais, no período de 23 de Abril de 2015 à 06 de Junho de 2015.
Foram escolhidos aleatoriamente dois experimentos a fim de demonstrar o perfil de variação das temperaturas ambiente, na cobertura, no ambiente interno do destilador, na bacia e da produção ao longo do dia. São mostradas nas Figuras 7 e 8 o experimento 10, o perfil das temperaturas e da produção.

Figura 7 - Variação das temperaturas de ambiente, na cobertura, na água e dentro do destilador ao longo do dia

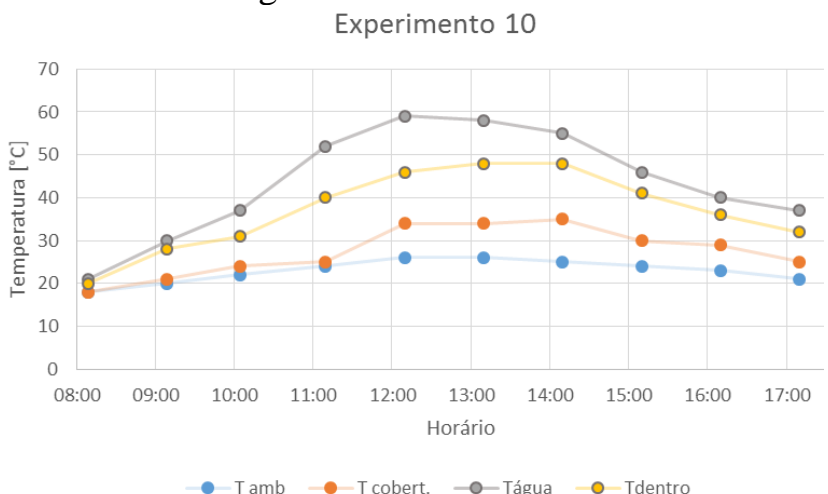

Fonte: Autor (2015).

Figura 8 - Variação do volume de destilado ao longo do dia

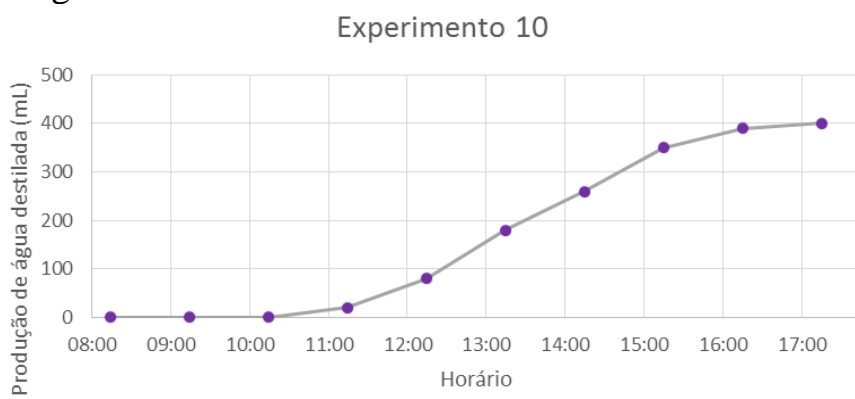

Fonte: Autor (2015).

Para o experimento 13 o perfil das temperaturas e da produção ao longo do dia são mostrados nas Figuras 9 e 10.

Os perfis observados seguem a mesma tendência, sendo que a produção de destilado se inicia por volta de 11:00 horas, e as temperaturas de pico estão entre 12:00 e 14:00 horas. 
Figura 9 - Variação das temperaturas de ambiente, na cobertura, na água e dentro do destilador ao longo do dia.

Experimento 13

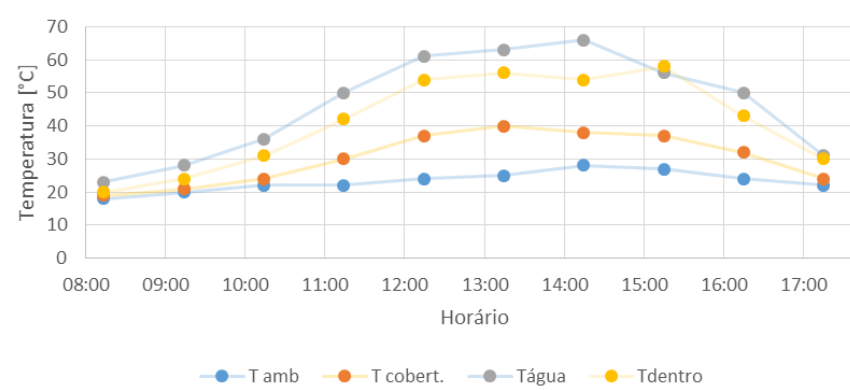

Fonte: Autor (2015).

Figura 10 - Variação do volume de destilado ao longo do dia

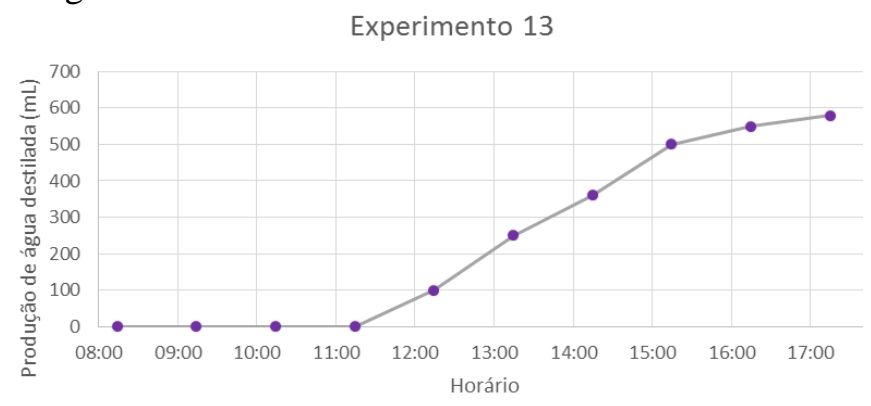

Fonte: Autor (2015).

\section{CONCLUSÃO}

A cidade de Uberaba apresenta alta incidência solar, fator fundamental para $\mathrm{o}$ desenvolvimento de um destilador solar nesta região. Mesmo com a fase experimental ter sido realizada durante o outono, foram obtidos resultados satisfatórios.

Dentre os dezessete experimentos realizados, a máxima produção obtida foi para o experimento treze tendo esse $56,5 \%$ de eficiência de produção de destilado, sob as condições de menor nível de profundidade de bacia, nível intermediário para a espessura do isolamento e salinidade. É válido ressaltar que a eficiência máxima estimada para o destilador solar construído é de aproximadamente $60 \%$ considerando as perdas sofridas pela radiação solar medida na atmosfera e realmente incidente ao destilador.
De acordo com análise estatística feita através de planejamento composto central e análise de superfícies de resposta, as variáveis de maior influência no processo são respectivamente profundidade da bacia, salinidade e espessura do isolamento, resultado concordante com a literatura estudada.

Os resultados da análise de qualidade da água obtidos se enquadram na especificação de água de rio doce, de acordo com as análises de $\mathrm{pH}$ e condutividade realizadas. Porém, são necessários testes mais rigorosos para defini-la como apropriada para consumo humano. Pela análise sensorial das propriedades organolépticas a água obtida mostra-se incolor, inodora e insípida.

Os desafios enfrentados para a construção e funcionamento do projeto foram superados da maneira mais econômica e acessível, visando praticidade.

Através dos resultados obtidos com este trabalho e os estudos realizados para tal, são propostos para trabalhos futuros: a realização de mais testes para avaliar a potabilidade da água destilada, a construção de um ambiente controlado, com uma fonte de radiação artificial, para realizar a avaliação de outros parâmetros sobre a produção de um destilador solar, como a velocidade do vento e radiação solar.

\section{NOMENCLATURA}

$a$ - vértice da pirâmide (m)

$A_{s}$ - Área útil do destilador $\left(\mathrm{m}^{2}\right)$

$C_{w g}$ - Capacidade térmica do sistema $\left(\mathrm{J} \mathrm{kg}^{-1} \mathrm{~K}^{-1}\right)$

$H$ - Altura da pirâmide (m)

$h$ - vértice da pirâmide $(\mathrm{m})$

$H_{s}$ - valor da radiação solar $\left(\mathrm{w} \mathrm{m}^{-2}\right)$

$k_{b}$ - condutibilidade do material

$L$ - Lado da base da pirâmide (m)

$P$ - produção de água destilada $\left(\mathrm{L} \mathrm{m}^{-2}\right)$

$q_{c}$ - calor transferido por convecção ( $\mathrm{W} \mathrm{m}^{-2}$ )

$q_{e}$ - calor transferido por evaporaçãocondensação ( $\mathrm{W} \mathrm{m}^{-2}$ )

$q_{r}$ - calor transferido pela radiação $\left(\mathrm{W} \mathrm{m}^{-2}\right)$ 
$T_{a}$ - temperatura ambiente $\left({ }^{\circ} \mathrm{C}\right)$

$T_{w}$ - temperatura da água $\left({ }^{\circ} \mathrm{C}\right)$

$\alpha$ - ângulo de inclinação da pirâmide

$\alpha_{g}$ - absorbância da cobertura

$\alpha_{w}$ - absorbância da bacia

$\lambda$ - calor latente de evaporação água $\left(\mathrm{J} \mathrm{kg}^{-1}\right)$

$\tau$ - Transmitância da cobertura

$\eta$ - rendimento de um destilador

$T_{\max }$ - Temperatura máxima anual média $\left({ }^{\circ} \mathrm{C}\right)$

$T_{\min }$ - Temperatura mínima anual média $\left({ }^{\circ} \mathrm{C}\right)$

\section{REFERÊNCIAS}

ALVES, R. S. Estudo sobre a dessalinização de águas salobras utilizando a energia solar. 32 f. Monografia (Engenharia Química) - Universidade de Uberlândia, Uberlândia. 2008.

ASTM D 1141, Standart Practice for the preparation od Substitute Ocean Water. 1998.

CRAVO, J. G.; CARDOSO, H. E. Projeto de dessalinização de solos e água. Nota Técnica n²1. Brasília/DF: SRH/MMA, 1996.

LUIZ, A. M. Como aproveitar a energia solar. $1^{a}$ ed., São Paulo, Editora Edgard Blucher, 191 p, 1985.

MALUF, Alexandre Prata: Destiladores Solares no Brasil. Faculdade de Engenharia Mecânica. Universidade Federal de Lavras, 2005. Monografia.

MINISTÉRIO DA SAÚDE. Portaria $\mathbf{N}^{\circ}$ 2.914, de 12 de Dezembro de 2011. Disponível em: <http://bvsms.saude.gov.br/bvs/saudelegis/gm /2011/prt2914_12_12_2011.html>. Acesso em Maio de 2015.

MOTA, Suetônio e ANDRADE, Márcio Antônio Nogueira. Uso da destilação solar no tratamento de águas contaminadas com microrganismos. Aplicações às pequenas comunidades. Revista Tecnologia, número 7, 1986.
SAMEE, M. A.; MIRZA, U. K.; MAJEED, T., AHMAD, N. Design and performance of a simple single basin solar still, Renewable and Sustainable Energy Reviews 11, p. 243249, Islamabad, Paquistão, 2005.

Tiwari, A. K., \& Tiwari, G. N. (2007). Thermal Modeling Based on Solar Fraction and Experimental Study of the Annual and Seasonal Performance of a Single Slope Passive Solar Still: The Effect of Water Depths. Desalination, 207, 184-204.

\section{AGRADECIMENTOS}

À Universidade Federal do Triângulo Mineiro em apoio ao projeto, fornecendo os laboratórios, equipamentos e meios necessários para a realização deste projeto. Aos professores orientadores Prof. Dr. Davi Leonardo de Souza e Prof. Dr. José Luiz Vieira Neto que nos ajudaram nesta jornada acadêmica com seu apoio e confiança. Á professora Profa. Dra. Kássia Graciele dos Santos por sua cooperação e contribuição. E ao técnico de laboratório Marco Antônio por seu apoio. 